\title{
Vicente Sáenz: presencia y exilio mexicano
}

Dr. Mario Oliva-Medina

Catedrático, Investigador

Instituto de Estudios Latinoamericanos

Universidad Nacional

Costa Rica

\section{Resumen}

En este ensayo se presenta una biografía intelectual de Vicente Sáenz, costarricense radicado en México, personaje de múltiples facetas. Este trabajo busca rescatar la vida y hechos de Vicente Sáenz del olvido de nuestra memoria colectiva, a este importante pensador, periodista, editor, profesor y político.

Palabras clave: Vicente Sáenz, pensamiento costarricense, exilio costarricense en México, Temas de Nuestra América, Cátedra del Exilio.

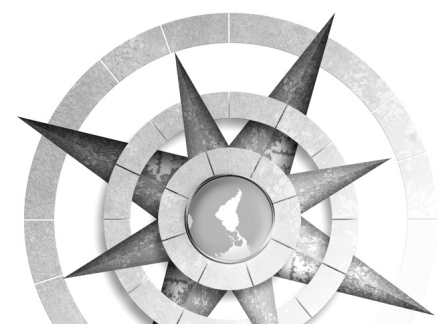

This essay presents an intellectual biography of Vicente Sáenz, a Costa Rican based-in Mexico multi-faceted character. This paper seeks to release from forgetfulness the life and deeds of this outstanding thinker, journalist, editor, professor and politician in order to bring him back into our collective memory.

Keywords: Vicente Sáenz, Costa Rican thought, Costa Rican exile in México, Temas de Nuestra América, Exile Reseach Group

Múltiples y variadas pueden parecer las razones por las cuales el costarricense Vicente Sáenz se vio atraído, desde muy temprano hasta el final de su vida, por la nación mexicana. Los trabajos y los días en México se fueron hilvanando acordes con sus labores como periodista, editor, profesor, 
político y pensador. La información que tenemos hasta ahora sobre esta relación puede considerarse como muy tangencial y primaria, lo cual quisiera zanjar de manera parcial en este ensayo, refiriéndome, además a sus ajetreos intelectuales y políticos o, dicho de otro modo, presentando una biografía intelectual, porque es lo que básicamente fue este personaje: un intelectual. De acuerdo con el crítico y ensayista palestino Edward Said,

[...] para mí el hecho decisivo es que el intelectual es un individuo dotado de la facultad de representar, encarnar y articular, un mensaje, una visión, una actitud [...] El intelectual actúa de esa manera partiendo de los siguientes principios universales: todos los seres humanos tiene derecho a esperar pautas razonables de conducta en lo que respecta a la libertad y la justicia por parte de los poderes o naciones del mundo, y las violaciones deliberadas o inadvertida de tales pautas deben ser denunciadas y combatidas con valentía. ${ }^{1}$

Una proporción en la debilidad historiográfica sobre esta figura se logró

1 Edward, Said, Representaciones de los intelectuales, Caracas, editorial Ramdom House Mondadori, 2010, pp. 30 y 31. remediar un tanto hace apenas un par de años, cuando inició junto con otros académicos, la recuperación y reflexión sobre su vida y su obra con el objetivo de llenar esta laguna en nuestra memoria colectiva. ${ }^{2}$

Vicente Sáenz Rojas nació en San José de Costa Rica, en 1896, y murió en la ciudad de México, en 1963. Antes de cumplir los 20 años de edad, viajó a Estados Unidos, en donde impartió lecciones de español y francés en los colegios Repton School, Tarry-Town-on Hudson en Nueva York y Carton Academy en Nueva Jersey.

A principios de 1917 hubo un golpe de Estado en Costa Rica por parte de los hermanos Tinoco Granados. El joven Sáenz, ya reconocido escritor de un par de novelas, ${ }^{3}$ inició una intensa

2 Me refiero principalmente al esfuerzo editorial desarrollado por las universidades públicas costarricenses al publicar durante el año 2013, una colección Coincidente con el 50 aniversario de la muerte de Vicente Sáenz Rojas, se publicaron seis libros: dos dedicados al autor: Tras las huellas de Vicente Sáenz; (varios autores); Expediente 1533: el presidio de Vicente Sáenz en 1939 (Mario Oliva); y la reedición de cuatro de sus obras: Rompiendo cadenas (1933); Traidores y déspotas de Centroamérica (1920); Rompiendo cadenas. (1933); España heroica (1938); El grito de Dolores y otros ensayos (1959). Prologados con estudios de académicos, como: Gilberto Lopes, John Saxe, Margarita Silva, Iván Molina y Mario Oliva.

3 Las novelas de corte romántico son: Cuentos de amor y de tragedia. Imprenta y encuadernación de Falco y Borrasé, San José de Costa Rica 1920; El 
y sostenida campaña de condenación y de protesta contra el régimen de los $\mathrm{Ti}$ noco. La recopilación de los escritos en la prensa norteamericana se transformó en su primer libro dedicado al autoritarismo en los países de la región, bajo el título incendiario de Traidores y Déspotas de Centroamérica. Este libro tiene una historia singular desde el punto de vista editorial. Durante la Primera Guerra Mundial, en Estados Unidos, las garantías y libertades estaban suspendidas. Por esta razón, a raíz de la primera edición de tal obra en 1918, el cual contenía juicios del gobierno estadounidense contra Centroamérica, Sáenz cae en desgracia y con él su obra, que si bien se publicó, tuvo circulación censurada. Sáenz se salvó de ir a la cárcel y pudo viajar a México, mientras que la edición de 3500 ejemplares desapareció por completo. ${ }^{4}$

México recibió a Sáenz por primera vez en 1918, invitado por el propietario de El Universal, el ingeniero Félix F. Palavicini, con quien había hecho amistad meses antes en Estados Unidos. Ocupó, en el entonces primer diario de México, el cargo de secretario de redacción

tío Samuel en las páginas de nuestra historia. Imprenta María de Lines, San José de Costa Rica. 1921.

4 Véase Vicente Sáenz Rojas. Traidores y déspotas de Centroamérica, EDUPUC, 2013, pp. 15-20, prólogo Mario Oliva Medina. La edición que se conoce es la de 1920, Imprenta y Librería y Encuadernación de Falcó y Borrasé, San José, Costa Rica. y fundó y dirigió su página en inglés, continuando su lucha contras las tiranías de Centroamérica.

A finales de 1919, derrocados los Tinoco, Sáenz volvió a Costa Rica e inició trabajos en el periódico La Prensa, su pluma seguía el camino de la denuncia de los abusos de las clases poderosas. En 1921 fue electo diputado al Congreso Constituyente Federal de Centroamérica, reunido en Tegucigalpa, Honduras, en conmemoración de los cien años de la Independencia. En ese mismo año publica Cartas a Morazán, utilizando un recurso estilístico de la época, como era la ficción de escribirle al General sobe todos los movimientos relacionados con dichas reuniones federativas, de los que apoyan las ideas unionistas y de aquellos que la rechazan. En Costa Rica fundó el periódico La Opinión, en 1924 y regresó, años más tarde luego de una segunda estancia de siete años en México (entre 1928 y1935), acompañado de su primera esposa Dora Jiménez Guardia, y de su pequeño hijo Guillermo, quien cae gravemente enfermo y fallece. De nuevo en Costa Rica, prosigue su labor periodística y conjuga su habilidad editorial al promover la revista Liberación (1935-1937) con la fundación del Partido Socialista Costarricense a mediados de 1935, junto a un grupo de intelectuales y de artesanos y obreros urbanos. 
En las páginas de esa revista, discurre el ideal político del socialismo costarricense, ligado en sus orígenes a otro movimiento social mayor en América Latina: la Alianza Popular Revolucionaria Americana (APRA). La revista y sus colaboradores, nacionales y extranjeros, formaron parte de una red que se expresaba a partir de coordenadas ideológicas como el nacionalismo, el antiimperialismo y la transformación social, con un fuerte componente de intervención estatal. ${ }^{5}$

El año de 1939 marca un hito en la historia personal e intelectual de Sáenz; al regresar de uno de sus viajes a la España republicana, derrotado por el desenlace de aquel conflicto, se vio envuelto en un intento de homicidio al disparar tres tiros a quemarropa a un conocido comerciante alemán Herbert Knohr, jefe del nazismo en Costa Rica. El motivo de dicho acontecimiento, fue un ataque, un arrebato de celos, ya que este último tenía un romance con su esposa, una joven y hermosa mujer de una de las familias más connotadas de la sociedad costarricense de la época, de nombre Dora Jiménez Guardia. Vicente Sáenz fue a la cárcel y estuvo cien días preso; toda su defensa la en-

5 Véase Mario Oliva, Liberación: revista centroame ricana de vanguardia (1935-1937). Tras las Huellas de Vicente Sáenz, A los cincuenta años de su muerte, Editoriales Universitarias Públicas Costarricenses, 2013. San José de Costa Rica, pp. 51-93 volvió en una retórica de carácter político y moral. Sin embargo, su salida de prisión de manera tan pronta se debió, en parte, a la presión ejercida por la solidaridad desarrollada principalmente por intelectuales de toda América y España que reclamaron su libertad; y por otra; al peso ejercido por la correlación de fuerzas a nivel mundial: el mundo se dividía entre fascismo y democracia y Sáenz era un defensor de esta última. ${ }^{6}$

Luego de su salida de las celdas de la Penitenciaría central de San José, Costa Rica, Sáenz emprendió un largo y definitivo autoexilio. En el año de 1940, viajó con sus tres hijos de manera breve a Estados Unidos, y en seguida se instaló en México hasta su muerte en 1963. De acuerdo con el Registro Nacional de Extranjeros (RNE) en México, Vicente Sáenz Rojas entró a la capital mexicana como turista el 30 de julio de 1940, proveniente de Nueva York. Declaró ser originario de San José el objetivo de su estancia fue tomar apuntes sobre el México de esos años.?

El 7 de marzo de ese año había recibido una carta alentadora del dirigente obrero Vicente Lombardo Toledano,

6 Mario Oliva, Expediente 1533. El presidio de Vicente Sáenz, San José, EDUPUC, 2013.

7 Véase José Francisco Mejía y Laura Beatriz Moreno, "El exilio Costarricense en México en la década de 1940", en Cuadernos Americanos, núm.152, año XXXIX, vol., 2 abril-junio, 2015, p. 61. 
en donde éste expresa su propósito de conocer cuál era su situación personal, para que le diga con toda franqueza y confianza con que se hablan los amigos, la forma en que podría ayudarle en esos momentos tan difíciles por los que estaba pasando. ${ }^{8}$

\section{El 25 de marzo, Sáenz, aún en Costa} Rica, escribe al dirigente mexicano, con una retórica alegoría en tan difícil situación en la que se encontraba, y dice: "estoy profundamente satisfecho de haber rubricado con tres fogonazos pacificadores mi actuación antiimperialista [...] pero la intención de su nota era de pedir ayuda a los mexicanos para poder salir de Costa Rica ante la precaria situación en que se hallaba al salir de la cárcel, durante diez meses había hecho esfuerzos que consideraba sobrehumanos para enfrentarse a los enemigos y vencer los obstáculos que, por falta de medios económicos, hacían la lucha mucho más difícil. Por esos días, recibió ayuda de las Hispanas Confederas de Nueva York y de la familia de don Abel Camacho, gerente de la Editorial Iberoamericana. Familia que sería la que asiste a sus tres hijos, misma que lleva a Nueva York. En la segunda quincena de abril del año 1940, salió hacia esa ciudad. Para sufragar los gastos vendió sus libros y pedía dinero a sus compañeros

8 Vicente Lombardo Toledano, Correspondencia a Vicente Sáenz, 7 de marzo de 1940, Archivo Universidad Obrera Lombardo Toledano, México. mexicanos para realizar su viaje e iniciar una campaña antifascista y antitotalitaria. Aseguraba que la ayuda que se le diera sería recompensada con creces por lo que estaba en capacidad de hacer y escribir después de la experiencia y el calvario que ha pasado"9

Tras una breve estancia en Nueva York, viajó a México y cumplió con aquella promesa de devolver con trabajo y acción política la ayuda brindada por sus compañeros mexicanos, con quienes durante la década anterior habían tenido la oportunidad de tranzar amistad, sobre todo con aquellos cercanos a Lombardo Toledano.

Muy pronto se casó en segundas nupcias con Clara Camacho Sarmiento, de nacionalidad colombiana, educada en Francia y en Estados Unidos, quien lo apoyó en todas sus actividades intelectuales y políticas, convirtiéndose así en su más apasionada colaboradora.

Su labor en México puede calificarse de intensa en los ámbitos cultural, educativo y político. Participó como miembro de distintas organizaciones científicas y literarias, y ocupó altas posiciones de confianza verdaderamente honrosas, cerca del ministro de Estado

9 Vicente Sáenz, Correspondencia a Vicente Lombardo Toledano, 26 de marzo de 1940, Archivo Universidad Obrera Lombardo Toledano, México. 
de la República Española, Julio Álvarez del Vayo, y en la Secretaría de Educación Pública de México, junto a don Luis Sánchez Portón, quien en 1941 lo elevó al cargo de miembro correspondiente de la Sociedad de Naciones. ${ }^{10}$

Actuó de lleno en las movilizaciones sociales desarrolladas en México con el líder obrero Lombardo Toledano, con el cual creó la Universidad Obrera de México, y fue parte del grupo de destacados intelectuales que escriben en órganos de difusión del pensamiento alternativo, socialista y comunista mexicano, como las revistas Cuadernos Americanos, Futuro, Humanismo y otras.

Respecto de su obra escrita, cabe mencionar una veintena de libros producidos desde 1920 hasta 1960; la mayor parte de ellos editada en México. ${ }^{11}$ Los temas son muy variados y corresponden a coyunturas particulares. Sin embargo, se perciben en ellos algunas, llamemos así, preocupaciones permanentes:

10 Entrevista Socialistas en el exilio. Cosas y hombres de Europa, Editorial Nueva Década, Costa Rica, p. 243.

11 Los siguientes fueron publicados fuera de México: Traidores y déspotas de Centro América, Buenos Aires, Imprenta Alsina, 1920; Cuentos de amor y de tragedia (novela), 1918; Norteamericanización de Centro América, San José de Costa Rica, Talleres de La Opinión, 1925; Cartas a Morazán, Honduras, 1921; España heroica, Nueva York, Editorial Iberoamericana, 1938 y La doctrina de Monroe frente a los nazis en América, 1823-1940, Nueva York, Editorial Iberoamericana,1940. desde su lucha contra las tiranías y la unidad centroamericana, pasando por sus reflexiones sobre el imperialismo y el antiimperialismo, hasta la Guerra Civil española y su antifascismo, como su preocupación por el pensamiento emancipatorio y de descolonización mental y cultural en la región.

Muchos de sus textos se encuentran desperdigados en periódicos y revistas en varios países del continente americano, Europa y Estados Unidos. Otro aspecto que limita por ahora su estudio es no contar con su archivo personal, que seguramente contiene información valiosa de sus densas relaciones epistolares con los más destacados intelectuales y políticos de su época como: Carlos Pellicer, Pablo Neruda, Alfonso Reyes, Víctor Raúl Haya de la Torre, Nemesio García Naranjo, Juan José Arévalo, Andrés Eloy Blanco, Isidro Fabela, monseñor Víctor Manuel Sanabria, Lázaro Cárdenas, Rómulo Gallegos, Jesús Silva Herzog, Alfonso Caso, Andrés Henestrosa, etc. Con lo anterior, pretendo subrayar y advertir que cualquier acercamiento a su pensamiento y acción es aún provisional si tomamos en consideración que la etapa de recuperación y compilación de su obra completa es tarea pendiente. Un número considerable de sus obras, son producto de su propia labor como editor, al fundar las

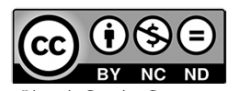


editoriales Liberación y América Nueva (ambas en la ciudad de México) que dirigió durante varios años en la década de los cuarenta y cincuenta, que nos permiten conocer materiales que nacieron y se desarrollaron paralelamente a su labor como pensador, periodista, profesor y conferencista; se trata de temas destacados de su época.

De esa labor editorial, debemos acotar su empeño por publicar obras de sobresalientes intelectuales que descollaron en la cultura mexicana y latinoamericana, como: Guatemala, la democracia y el imperio; Fábula del tiburón y las sardinas, y Anticomunismo en América Latina de Juan José Arévalo; Operación Guatemala de Raúl Osegued; Buena y mala vecindad de Isidro Fabela; Camino real, Julio de Armas; Vida del Mariscal Sucre, Diego Córdoba; Obras completas de Francisco Pimentel (Job Pim); De Bolivar a Dulles, Ricardo A. Martínez y Yolanda Caligaris, Alcázar de ensueño. Algunos de estos libros se agotaban rápidamente, lo que obligaba al editor a realizar reimpresiones permanentes.

Quiero ahora, expresar algunas consideraciones sobre el estudio de las ideas y el pensamiento latinoamericano en la región. La primera es que su atención ha sido un asunto mayoritariamente emprendido por filósofos -algunos politólogos- y, en menor medida, por historiadores. La segunda, que el panorama es bastante copioso si pesamos en los hallazgos y contribuciones que se han realizado en ciertas zonas, regiones o países donde contamos con obras generales dedicadas al pensamiento filosófico continental; sin embargo, es obvio que la misma es muy dispar, y las maneras de abordar la temática es diversa; nos faltan muchos caminos por recorrer. En la gran mayoría de países, no encontramos ni siquiera trabajos panorámicos sobre el pensamiento, cualquiera que sea la acepción que deseemos usar.

Parece haber cierto consenso en torno a la idea de que el pensamiento político es una forma de debatir sobre ciertos aspectos de la experiencia social en cualquier nivel de abstracción o sistematización. De ser así, es importante diferenciar entre la forma en que se aproximan al tema un filósofo y un historiador. Como al filósofo le atañen las ideas en la medida en que se puedan explicar racionalmente, tiende a buscar los límites de la razón. Al historiador le interesan los hombres que pensaban sobre la política en tanto individuos que actúan en el seno de una comunidad (intelectual, campesina, obrera u otra), cuya conducta está registrada y puede estudiar con ayuda de la reconstrucción 
histórica para mostrar en qué mundo vivían y cómo actuaban en él. Al historiador le preocupa la relación existente entre experiencia y pensamiento, entre la tradición que fija las normas de conducta en una sociedad dada y el proceso de abstracción de conceptos que se realiza para intentar entender e influir sobre ella. Un historiador puede fallar en este intento si cumple la función de un filósofo en vez de la suya propia ${ }^{12}$.

Por otra parte, en los últimos veinte años nos topamos con nuevas formas, o, mejor dicho, renovadas formas y conveniencias de enfrentar estos problemas de lo que significa la historia de las ideas. Me refiero específicamente a los aportes y auge de lo que conocemos como historia de los intelectuales o historia intelectual. ${ }^{13}$ Simplificando al máximo un asunto complejo, se trata de estudiar las formas de producción, circulación y consumo de las ideas, lo cual nos hace desplegar un enorme abanico de posibilidades de reflexión sobre el pensamiento latinoamericano. La renovación del interés reciente por la historia intelectual ha seguido, en especial, la vía de investigación impulsada

12 J.G.A., Pocock. Pensamiento político e historia, Madrid, Akal, 2011, p. 25.

13 Véase para este punto los trabajos de Francois Dosse, La marcha de las ideas, Valencia, España, Universidad, 2007.; La apuesta biográfica; [Paul Ricauter simplificando un asunto en extremo complejo, Los sentidos de una vida.] por Jean-Francois Sirinelli. Esta historia pretende ser a la vez "arqueología, geografía y genealogía”: arqueología para la búsqueda de las solidaridades originales y de las estratificaciones generacionales; geografía por la iluminación de los lugares de las redes de la producción intelectual; y genealogía por la puesta en evidencia de las relaciones de filiación que la vinculan al pasado ${ }^{14}$.

Para el historiador, los campos discursivos desbordan el estudio del pensamiento filosófico, para lanzarse a la prospección de todos los lugares y medios de sociabilidad, que se encuentran afectados cuando estudiamos las ideas y el pensamiento latinoamericano. Roger Chartier define una andadura que pretende conjugar una lectura hacia adentro y hacia afuera, descartando la concepción estereotipada que partiría de la idea de una significación unívoca de los textos, dejando de lado los diversos modos de apropiación y considerando la difusión de las ideas como una simple imposición. Muy por el contrario, según Chartier, no se puede disociar el proceso de difusión de las ideas del objeto mismo de esta difusión”. ${ }^{15}$

14 F. Dosse. La marcha de las ideas, op.cit.,p. 45.

15 Ibid., p. 145. 
Vamos ahora a otro asunto más particular, por donde se debate esta incursión o propuesta de trabajo, si aceptamos que una de las grandes formas de expresión del pensamiento en la región es el ensayo (asunto muy útil es el caso de nuestro autor), y como muestra Liliana Weinberg afirma que los estudiosos de este género van desde aquellos que atienden cuestiones compositivas y a la propia configuración y constitución interna de los textos, hasta los que se ocupan por inscribir el ensayo en distintos horizontes interpretativos y rastrear cuestiones históricas o de debate de ideas ${ }^{16}$. Se trata, entonces, de poner en relación texto y contexto.

Entre los temas predominantes, del ensayo de Vicente Sáenz, encontramos el americanismo: desde su primer libro Déspotas y traidores en Centroamérica (1918-1920), hasta Nuestra América en la cruz (1960), pasando por Cartas a Morazán (1922), Norteamericanización de Centroamérica (1925), Rompiendo cadenas (1933, 1951, 1962); Centroamérica en pie (1944); Hispanoamérica contra el coloniaje (1949); Auscultación hispanoamericana (1954); El grito de Dolores (1959) y Vidas ejemplares hispanoamericanas (1959).

16 Véase Liliana Weingerg, Estrategias del pensar, t. I, México, CIALC-UNAM, 2010, pp. 9-42.
Al decir de Joaquín García Monge, toma la ruta de los "santos laicos", los próceres de la independencia política y más tarde próceres de la descolonización cultural. La misma que en las latitudes centroamericanas abrirá el eximio hondureño americanista José Cecilio del Valle (1780-1834) al escribir, en 1822: "La América será desde hoy mi ocupación exclusiva. América de día cuando escriba: América de noche cuando piense. El estudio más digno de un americano es la América”.

El costarricense es uno de los más fieles exponentes de este tipo de escritura y pensamiento; su aporte es sustancial en términos del conjunto de ideas que materializa en un sistema articulado en torno al problema de América ${ }^{17}$.

La historiadora Margarita Silva, al prologar el Grito de Dolores y otros ensayos, expresa lo siguiente, refiriéndose a los escritos de Sáenz:

los ensayos de la obra renueva su significado y en su conjunto ofrecen una nueva lectura de la independencia, abordada desde distintos ángulos. Seis análisis de caleidoscopio muestran los argumentos del autor, que a su

17 Mario Zeledón Cambronero, Pensamiento americanista de Vicente Sáenz, (Tesis de Licenciatura en Filología Española, Universidad de Costa Rica), p. 25. 
vez constituyen los fundamentos sobre los que reposa la unidad del texto: el concepto de independencia como etapa de renacimiento aún no consumada, la Generación de 1810 como gestora de la independencia, la unidad hispanoamericana, como factor de la unidad cultural y la denuncia y el compromiso social de los intelectuales como factores $[. .$.$] en la lucha por la liber-$ tad de los pueblos oprimidos. ${ }^{18}$

Vicente Sáenz, interpreta los problemas más duros de la realidad que le corresponde vivir en términos económicos, políticos, sociales, de relaciones internacionales. Trata de explicar, buscar los antecedentes, es un hombre informado de los acontecimientos más relevantes de su tiempo. Es una prédica antidictatorial, denuncia la corrupción de los que detentan el poder interno y externo. En sus escritos desfilan, una por una, todas las dictaduras que sojuzgaban América. Demuestra que la historia de América Latina no es más que una larga y dolorosa lucha entre las paupérrimas mayorías explotadas y sus explotadores, apoyados éstos, las más de las veces, en los intereses foráneos. Por esta razón, varios de sus libros ha-

18 En Vicente Sáenz, El grito de Dolores y otros ensayos, Prólogo de Margarita Silva, San José, EDUPUC. 2013, pp 17,18 cen alusión a la explotación económica ejercida por el imperialismo norteamericano en sus más sutiles manifestaciones con Centroamérica y el resto del continente. Plantea la oposición entre la América pobre y la América opulenta, y busca las causas de esa oposición.

Busca en la tradición exaltando la vida y el pensamiento de nuestros hombres de letras y acción, de un modo que hoy conmueve, por su defensa de la dignidad americana: “Humanizar, pues, la biografía de nuestros máximos valores; bajarlos de sus monumentos ...llevarlos a las escuelas; sentirlos cerca de nosotros y de nuestros hijos; en la intimidad del hogar, darles su sitio, como seres vivos, en la evolución y en el progreso de cada pueblo hispanoamericano!". ${ }^{19}$

Este último era uno de sus tantos objetivos altruistas del estudio de lo propio. Seguramente esta interpretación se afincaba en sus lecturas de Bolívar, de Martí, de Montalvo, de Morazán, de Morelos. Se aparta del convencionalismo oficial con respecto a la historia y a la interpretación de los próceres. Su prosa es crítica y desmitifica.

Como también, desde muy joven -a penas con veinte y tantos años- se alejaba de toda

19 Vicente Sáenz, Vidas ejemplares hispanoamericanas, Editorial América Nueva, México, 1959, p. 12 
posibilidad de tutelaje, e intervencionismo de los Estados Unidos en nuestros países. "La formación y sensibilidad de Sáenz le permite captar, describir, documentar, analizar e interpretar a los actores, los monopolios, los bancos, corredurías y procesos eje alrededor de los que se estremeció el mundo, el hegemón estadounidense y América Latina, del Bravo a la Patagonia".20

Así se expresaba recientemente el estudioso en geo-estrategia John Saxe Fernández, de uno de los libros más influyentes publicados en América Latina sobre el imperialismo y el antiimperialismo durante los años treinta: Rompiendo cadenas cuya primera edición data de 1933; luego pasaron casi veinte años para su segunda edición en 1951; la tercera en 1961 y la cuarta un año después, en 1962.

Este libro fue precedido por otro no menos substancial: Norteamericanización de Centroamérica (1925) en el que analiza de manera punzante y profunda los tratados comerciales leoninos que firmaban los gobiernos del área con los Estados Unidos. El mismo Sáenz calificaba su escritura del modo siguiente:

20 Vicente Sáenz, Rompiendo cadenas, Prólogo de John Saxe Fernández, San José, EDUPUC, 2013, p. 19.
[...] Páginas patriótica de denuncia contra ciertos actores políticos quienes dejaban de senalar coautores responsables de la norteamericanización de Centro América, para dirigirse con mayor firmeza a determinados grupos políticos de eminencia criolla que han venido monopolizando, desde hace mucho tiempo, la dirección de los negocios públicos en el istmo. ${ }^{21}$

Esta corriente de pensamiento no la abandona hasta el final de su vida. En 1944, publica otro texto con un título incendiario en plena época de convulsiones mundiales: Centroamérica en pie, cuyo subtítulo es la marca de su contenido: Contra la tiranía, contra el crimen y la barbarie, contra el imperialismo en cualquiera de sus formas. Cinco años más tarde, en 1949 y bajo el auspicio de la Unión Democrática Centroamericana, publica Hispano América contra el coloniaje, un texto en que sintetiza la tensión histórica que se desarrolló en nuestros países con respecto a las potencias extranjeras (España, Inglaterra y los Estados Unidos) y va articulando los elementos más propios de nuestra conciencia y nuestro ser.

21 Vicente Sáenz. Norteamericanización de Centro América, San José, Talleres de La opinión, 1925, p 7. 
Un tercer tema es la Guerra Civil española. Sabemos que este hecho es el que con mayor fuerza ha conmovido a la intelectualidad mundial, constituyéndose en un parteaguas en favor o en contra de la República española. Nadie quedó al margen de la contienda, tampoco lo hizo Vicente Sáenz; es excepcional en el caso centroamericano por varias razones. En primer lugar, por ser el centroamericano que más escribió sobre la Guerra Civil Española durante y luego de finalizado el conflicto. Segundo, porque su obra, y muchos de sus escritos, fueron conocidos a través de los periódicos de la época, tanto en América como en España y en Estados Unidos y traducidos a otros idiomas.

Tres títulos aporta al proceso español, los cuales enriquecen su biografía intelectual: España heroica, que se publica en 1938 y consta de doce capítulos; en total, son más de trescientas páginas consagradas al conflicto español. También contiene trabajos producidos como parte de sus dos estancias en España: la primera, durante siete semanas en julio y agosto de 1936; y la segunda, realizada al año siguiente de febrero a septiembre de 1937. Permaneció un año en contacto con políticos, militares, escritores, artistas, altos funcionarios, campesinos y obreros españoles.
Otra obra que se publicó en 1942 es Cosas y hombres de Europa. Dos años más tarde, apareció Opiniones y comentarios de 1943. Ambas fueron redactadas y editadas en la capital mexicana; se incluyen varios escritos sobre la posguerra de España.

Puede afirmarse que el compromiso antifascista será asumido por este tipo de intelectuales, lo cual queda ratificado en el Segundo Congreso Internacional de Escritores Antifascistas, escritores adscritos o compañeros de viaje "confesos al partido Comunista, prueba del prestigio y creciente hegemonía de la inteligencia comunista durante la segunda república", 22 de la cual nuestro ensayista era uno más de los simpatizantes internacionales.

Otro rasgo de estos ensayos es su intento de tejer su reflexión en relación con la historia de América, en sus héroes que le cobijan para ponerlos en acción ante los acontecimientos españoles.

La segunda serie de ensayos de Vicente Sáenz pertenece a los años que van de 1940 a 1943; son producto de sus reflexiones de la posguerra civil española y del pleno ejercicio del poder de Franco. Esta serie adquiere una importancia extraordinaria, pues muy pocos escritores

22 Manuel Aznar Soler. II Congreso Internacional de Escritores Antifascistas (1937). Vol. II, Barcelona, Editorial 1AIA, 1978, p. 57. 
centroamericanos continuaron con este ejercicio de escritura.

El recuento de los ensayos de esta fase puede ser un colofón del pensamiento y la ensayística de Vicente Sáenz dedicada a la Guerra Civil española. En el periodo de posguerra, guarda varias características: el tono polémico de su escritura, un lenguaje directo donde los bríos literarios son los menos; aunque sin dejar de estar ausentes en el conjunto de sus textos, es palpable y constante que la construcción discursiva es parte de un conjunto de fenómenos de la formación discursiva global, en que se entremezclan sin total claridad núcleos discursivos o ejes como el fascismo, el totalitarismo, el nacionalsocialismo o el propio franquismo, en contraposición al comunismo, las utopías socialistas y la democracia. Sus ensayos posteriores son innumerables y reflejan la atracción que ejerció el proceso español en este escritor.

En mayo de 1942, un periódico de izquierda publicó una larga entrevista bajo el título "Socialistas en el exilio: Vicente Sáenz": "era la primera de una serie dedicada a conocer la personalidad y el pensamiento de camaradas que viven [...] la prueba de la emigración”, así rezaba la nota a dicha conversación. Una de las preguntas dice: ¿Cómo cree usted que influirá la cultura revolucionaria de América en la emigración española? Sáenz contesta con dos interrogaciones ¿Cuál cultura revolucionaria? ¿Cuál emigración española? No se puede hablar con exactitud de una cultura, de una filosofía revolucionaria americana. En su concepto, era mejor referirse a hechos revolucionarios en diversos países americanos, que tienen influencia sobre las diversas culturas que viven en el clima americano. Sobre la emigración española, distingue dos tipos: la "gachupinada", que sólo tiene en mira hacer pesetas o matrimonios ventajosos, y los migrantes, que no olvidan a sus compatriotas peninsulares, y que tarde o temprano pondrán en práctica, en la nueva República española de Trabajadores.

La otra interrogante era ¿Cree usted que la convivencia con los exiliados españoles tendrá alguna repercusión en el movimiento socialista del continente? Sáenz considera que sí, la experiencia histórica de los hombres de vanguardia, quienes no han tenido más remedio que salirse de su patria, servirá de orientación y de cauce para nuevos hechos y para nuevas realizaciones [...] esta convivencia ayudará, en todo caso, para que en las repúblicas hispanoamericanas se conozca y se rinda admiración a la España auténtica, que tanto había desprestigiado a los 
emigrantes sin ninguna inquietud espiritual. ${ }^{23}$

Al inicio de los años cuarenta el ensayista estaba radicado en México, y muy rápido entró en contacto con el exilio español que se encontraba en la capital mexicana, en donde ejerció el periodismo. Primordialmente su actividad se desenvolvió en el magisterio y como conferencista. Notable es su ejercicio como profesor en la Universidad Nacional Autónoma de México y en la Universidad Obrera, al lado de Lombardo Toledano, dirigente de amplia trayectoria en el movimiento obrero y sindical. Por último, y como epílogo a nuestra elocución, expongo un par de párrafos dedicados al tema de la recepción del pensar e ideario político de nuestro autor. Es muy sabido que durante dos siglos la configuración misma de la cultura continental más o menos giró en torno al problema de la recepción de ideas y de sistemas de pensamiento "externos". Las grandes preguntas de nuestra historia intelectual se vertebraron en torno a cómo se habían traducido, transculturado o hibridado en América Latina grandes movimientos de ideas como la ilustración, el romanticismo, el liberalismo o el socialismo. ${ }^{24}$

23 Vicente Sáenz. Cosas y hombres de Europa, México, Ediciones Liberación, 1942, p. 256.

24 Revista Politica de la memoria, Argentina, Cedinci, 2008, pp. 95-98.
Deseo plantear otro orden de cosas sobre la misma cuestión, si como hemos adelantado la obra escrita en libros, revistas y periódicos, u de otra modo en sus clases, sus conferencias, vertió cierto número de temas y problemas de su época también es sustancial desarrollar la investigación analizando "no solo su contenido dado a leer sino los soportes culturales y los usos diferenciados que se hacen de ellos desde la lectura privada silenciosa a la lectura pública” ${ }^{25}$

Al respecto, nos parece adelantada la visión que tenía Vicente Sáenz; su preocupación permanente de construir un lector en sus escritos y posibilitar acercamiento al horizonte de expectativa de la lectura, de igual modo con premonición desde su primer libro y muchos otros fue recogiendo variadas opiniones, comentarios, reflexiones, crítica de sus textos facilitando con ellos la investigación de lo que grandes críticos llaman la estética de la recepción, que permite, entonces, acercarnos a las prácticas cotidianas que las élites intelectuales de la primera mitad del siglo veinte. Fue mucha la recepción que acusaron intelectuales, escritores, políticos, periodistas y personajes influyentes, dejando materiales realmente significativos que para nosotros son parte de la historia de

25 Ibid., p. 160. 
un intelectual y de la historia intelectual que se está construyendo en esta parte del planeta.

Entre sus obras más leídas en su época; están las ya mencionadas; España heroica (1938), Rompiendo cadenas (1933), Guión de historia contemporánea dos tomos (1941,1942). Los dos últimos fueron editados en México, y profusamente difundidos en los círculos políticos de izquierda para todo el continente americano. Los tres textos suman más de mil páginas y tuvieron una circulación extraordinaria (alrededor de 65.000 ejemplares). Se trata entonces de uno de los autores más leídos en habla castellana.

"El Popular" expresa sobre uno de sus libros lo siguiente: "Basta hojear el índice de "Guión de historia contemporánea", para calibrar su importancia. Allí no hay ningún propósito sectario ni banderizo. Es una obra maestra de orientación, de documentación y de crítica [...]". Parecidos juicios aparecieron en publicaciones periódicas, como: El Universal, El Universal Gráfico, Revista Todo, Revista Hoy, Revista de revistas, El Universal Ilustrado, Letras de México, Cuba Contemporánea, La voz de Nueva York, entre muchas otras.
Permítaseme poner dos ejemplos contrastantes de lo que quiero decir cuando hablo de la recepción del ideario americanista y político de Vicente Sáenz. El primero corresponde a su coetáneo Pablo Neruda: "Vicente Sáenz, honor de Costa Rica, defensor incansable de la libertad de Centroamérica, reúne en sus libros, con su palabra de castigo y de justicia, el palpitante archivo de esta época de agonía”. ${ }^{26}$

El segundo corresponde a Ernesto Che Guevara, en un registro de sus lecturas que pretendía fortalecer su conocimiento y su visión de América. Lo destacó al mencionar a diversos pensadores americanos. El guerrillero había leído Raíz y Alas, de José Martí. El guerrillero leyó con atención el texto de Sáenz y a la par que lo comentó, le crítica:

si el folleto tiene algún peso, es el parangón final que hace con ciertos políticos adocenadas, contemporáneos nuestros. Llamar iguales que Martí a Rómulo Betancourt y Haya de la Torre es un insulto al hombre que vivió en el monstruo y le conoció la entraña, aun cuando La entraña era mucho menos negra y pestilente que la actual. Mejoraría

26 Vicente Sáenz, Cosas y hombres de Europa, México, Ediciones Liberación, 1942, p. 249. 
mucho el libro sin la invocación final". ${ }^{27}$

Como todo gran pensador y político, es sometido a diversas lecturas e interpretaciones y es precisamente allí donde radica parte de su riqueza y grandeza. En los últimos años la crítica académica de nuestro biografiado y de modo muy conveniente ha venido ocupándose de él abordando su producción utilizando algunos juegos de los métodos de la subjetividad y el sicoanálisis para desentrañar ciertos aspectos de su escritura, de su pensamiento, cuestionables es así como el historiador Denis Arias, abre una panorama polémico cuando analiza el antifascismo de Sáenz en los años inmediatamente anteriores a la Segunda Guerra Mundial:

era común que Sáenz denigrara "lo femenino" al pensar la cuestión nacional socialista desde diferentes ángulos, tanto cuando describió como traición putesca y perfumada de las elites "prostituidas" el mostrarse ambiguas frente a la defensa de la democracia, haciéndole el juego de las potencias "fascistas", como cuando acusó de "intelectuales afeminados" a quienes no asumían el compro-

27 Consulta:<WWW.Cadenagramonte.cubaweb. $\mathrm{cu} / \mathrm{p} 4>$. miso político de defender al "pueblo", la soberanía y la democracia frente a la amenaza nazi. ${ }^{28}$

En 1955, en uno de sus últimos libros publicados en vida -América hoy como ayer-, hacía repaso de su proceder y de su escritura:

[...] de mí sé decir que en moza edad, sin quitar puntos ni comas, empezaría de nuevo: con los mismos libros; con la misma decisión; con el mismo ímpetu igual contra déspotas y vende patrias; con mi devoción inmarcesible por lo nuestro, lo de ayer y lo de hoy, superando, mejorando, apegado a la justicia y al derecho, sin que ello implique desdén a otras civilizaciones, sino lucha incesante para que a nuestra cultura se le dé su sitio en el bloque más amplio de la cultura universal. ${ }^{29}$

Según los estudios recientes sobre el exilio, no es posible vivir un desexilio total ni mucho menos permanente el exiliado siempre está ligado mucho o poco a su tierra, a su cultura, a sus costumbres. En un hecho insólito, Vicente Sáenz Rojas, a fines de los años cincuenta, aceptó ser candidato a vicepresidente de

28 Denis, Arias. Utopías de quietud, San José de Costa Rica, EUNED, 1911, p. 200.

29 Vicente, Sáenz, América hoy como ayer, Bogotá, Editorial América Nueva, 1955, pp. 165 y 66. 
Costa Rica de un partido independiente y minoritario, sin ni siquiera volver al país. Decimos inexplicable de alguien que había tenido que abandonar su país veinte años antes con esporádicos y fugaces estancias; no puede, creemos nosotros, sostenerse este evento sin tener en consideración este enorme lastre que significa el exilio en un ser humano común y corriente, o como el caso que nos ocupa un intelectual probado por palabra, y su acción.
De algún modo he tratado de hablar de la obra y vida de un intelectual de enorme trascendencia en su época, y con plena vigencia si consideramos que muchos de sus planteamientos y soluciones a los problemas de América tienen plena actualidad. Pero sin olvidar que su estudio debe abarcar con todo rigor la densidad de sus aportes como sus ambigüedades, contradicciones, tensiones que le son propias a un pensar en movimiento, y que las coordenadas espacio temporales de las dinámicas sociales, políticas y personales permiten descubrir en sus textos y su vida la complejidad de dichas reflexiones que están en curso. 